\title{
Exploiting bacterial outer membrane vesicles as a cross-protective vaccine candidate against avian pathogenic Escherichia coli (APEC)
}

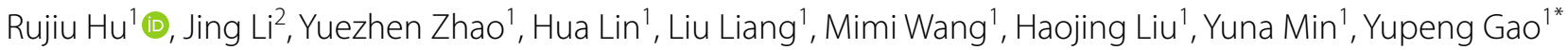
and Mingming Yang ${ }^{1 *}$

\begin{abstract}
Background: The well-known fact that avian pathogenic Escherichia coli (APEC) is harder to prevent due to its numerous serogroups has promoted the development of biological immunostimulatory materials as new vaccine candidates in poultry farms. Bacterial outer membrane vesicles (OMVs), known as spherical nanovesicles enriched with various immunostimulants, are naturally secreted by Gram-negative bacteria, and have gained much attention for developing effective vaccine candidates. Recent report has demonstrated that OMVs of APEC O78 can induce protective immunity in chickens. Here, a novel multi-serogroup OMVs (MOMVs) vaccine was developed to achieve cross-protection against APEC infection in broiler chickens.

Results: In this study, OMVs produced by three APEC strains were isolated, purified and prepared into MOMVs by mixing these three OMVs. By using SDS-PAGE and LC-MS/MS, 159 proteins were identified in MOMVs and the subcellular location and biological functions of 20 most abundant proteins were analyzed. The immunogenicity of MOMVs was evaluated, and the results showed that MOMVs could elicit innate immune responses, including internalization by chicken macrophage and production of immunomodulatory cytokines. Vaccination with MOMVs induced specific broad-spectrum antibodies as well as Th1 and Th17 immune responses. The animal experiment has confirmed that immunization with an appropriate dose of MOMVs could not cause any adverse effect and was able to reduce bacteria loads and pro-inflammatory cytokines production, thus providing effective cross-protection against lethal infections induced by multi-serogroup APEC strains in chickens. Further experiments indicated that, although vesicular proteins were able to induce stronger protective efficiency than lipopolysaccharide, both vesicular proteins and lipopolysaccharide are crucial in MOMVs-mediated protection.
\end{abstract}

Conclusions: The multi-serogroup nanovesicles produced by APEC strains will open up a new way for the development of next generation vaccines with low toxicity and broad protection in the treatment and control of APEC infection.

Keywords: Avian pathogenic E. coli (APEC), Outer membrane vesicles, Vaccine, Cross-protection, Immune response, Multi-serogroup

*Correspondence: gaoyupeng112@sina.com; biodna@126.com

${ }^{1}$ College of Animal Science and Technology, Northwest A\&F University, Yangling 712100, Shaanxi, China

Full list of author information is available at the end of the article

\section{Background}

Escherichia coli $(E$. coli $)$ is a commensal bacteria in human and animal intestine as well as a common zoonotic pathogen. Avian pathogenic E. coli (APEC) refers to $E$. coli strains that can cause extraintestinal diseases in chicken and other avian species [1]. As a major

(c) The Author(s) 2020. This article is licensed under a Creative Commons Attribution 4.0 International License, which permits use, sharing, adaptation, distribution and reproduction in any medium or format, as long as you give appropriate credit to the original author(s) and the source, provide a link to the Creative Commons licence, and indicate if changes were made. The images or other third party material in this article are included in the article's Creative Commons licence, unless indicated otherwise in a credit line to the material. If material is not included in the article's Creative Commons licence and your intended use is not permitted by statutory regulation or exceeds the permitted use, you will need to obtain permission directly from the copyright holder. To view a copy of this licence, visit http://creativeco mmons.org/licenses/by/4.0/. The Creative Commons Public Domain Dedication waiver (http://creativecommons.org/publicdomain/ zero/1.0/) applies to the data made available in this article, unless otherwise stated in a credit line to the data. 
bacterial pathogen in the poultry industry worldwide, APEC can cause typical colibacillosis in broiler chickens, such as colisepticemia, granuloma, air sacculitis, pericarditis and cellulitis [2]. APEC can infect chickens of different types and ages and lead to high morbidity and mortality rates in young chickens, resulting in huge economic losses every year [3]. Furthermore, a number of studies have shown that APEC may act as a human pathogen because they share some homologous virulence genes with human extraintestinal pathogenic E. coli [4-6]. Currently, prevention and treatment strategies of avian colibacillosis are commonly conducted based on the use of antibiotics. However, with the gradual prohibition of antimicrobial drugs in animal husbandry and the emergence of multidrug-resistant bacteria, it becomes difficult and costly to control APEC infection [7]. In addition, drug residues and resistant gene transfer may pose a great threat to human health [8]. Hence, it is urgently needed to search alternative preventive strategies to ameliorate APEC infection.

Vaccination is considered the most effective and economical means of controlling infectious diseases. Many vaccine candidates have been developed against APEC infection in chickens, including inactivated, live attenuated and subunits vaccines [9]. Inactivated vaccines were initially developed by killing the live whole-bacteria, which have not been widely used because of their low protective efficacy. Live attenuated APEC vaccines can provide stronger protection than inactivated vaccines. However, they have many obvious disadvantages, such as poor safety and short-term protection. As for the subunit vaccines, although they are generally safe, their application limited due to the high cost and complicated production process [10]. Moreover, these vaccines are not able to provide effective cross-protection against infections induced by multi-serogroup APCE strains [1, 9]. Since APCE strains have numerous serogroups and are widely distributed, an effective cross-protective vaccine is needed for broad-spectrum protection.

Vaccines based on outer membrane vesicles (OMVs) have gained increasing attention for preventing bacterial infections. OMVs are spherical vesicles with a bilayered proteolipid structure, which are naturally secreted by Gram-negative bacteria [11]. These vesicles contain immunoactive molecules, including cell-wall components, membrane proteins, cytoplasmic proteins and bacterial nucleic acids [12]. Some of these components nanosized are capable of eliciting antigen-specific immune responses [13, 14]. Because of the highly biocompatible nanosized structures and the naturally enriched immunogenic components, bacterial OMVs are widely considered as promising candidates for the next generation vaccine. Recent studies have shown that
OMVs derived from many Gram-negative bacteria, such as Pseudomonas aeruginosa [15], Salmonella typhimurium [16], Klebsiella pneumoniae [17], and Shigellae [18], are able to induce strong protective immunity in animal models of bacterial infection. Furthermore, several studies have suggested that vaccination with OMVs confers cross-protection against many serogroups of the same pathogen $[15,19]$. Neisseria meningitides-derived OMVs vaccine has been licensed worldwide for controlling meningococcal B disease in humans [20].

OMVs produced by $E$. coli $\left(\mathrm{OMV}_{\mathrm{EC}}\right)$ have been observed in many studies [21-23]. Various heterogeneous cargoes, including virulence factors, immunomodulatory factors and quorum-sensing signaling molecules, were identified in $\mathrm{OMV}_{\mathrm{EC}}$, indicating that the vesicles are associated with the physiology and pathogenesis of the bacteria $[24,25]$. The protective immunity of $\mathrm{OMV}_{\mathrm{EC}}$ also has been confirmed in mouse model of bacterial infection $[22,26]$. Hence, we reasonably speculated that OMVs produced by APEC $\left(\mathrm{OMV}_{\mathrm{APEC}}\right)$ could be used as the candidate antigens for vaccines against APEC infection. Recently, Wang and colleagues demonstrated that the single serogroup OMVs of APEC O78 can induce protective immunity against APEC O78 infection in chickens [27]. However, due to the diversity of APEC serogroups, it may be difficult to achieve $100 \%$ protective efficacy against multi-serogroups with a single serogroup $\mathrm{OMV}_{\mathrm{APEC}}$. Among the known serogroups of APEC, O1, $\mathrm{O} 2$ and $\mathrm{O} 78$ are predominantly associated with chicken colibacillosis outbreaks across the world $[1,9]$. Thus, the majority of APEC infection could be controlled by a cross-protective vaccine against these three serogroups.

Therefore, in the current study, we tried to obtain purified $O M V_{\text {APEC }}$ from three APEC serogroups, and then develop a novel multi-serogroup $\mathrm{OMV}_{\mathrm{APEC}}$ (MOMVs) vaccine by formulating a mixed immunogen with these three different $\mathrm{OMV}_{\mathrm{APEC}}$. We investigated the safety and immunogenicity of the MOMVs as well as the crossprotective effect of MOMVs vaccination in the chicken model of APEC infection. Our goal is to use OMVs produced by natural APEC strains for the development of practical broad-spectrum vaccines against multi-serogroup APEC infections.

\section{Results}

\section{Preparation and characterization of MOMVs}

Isolation and purification procedures of bacterial OMVs are shown in Fig. 1a. A large vesicle pellet (Fig. 1b) was obtained from the culture supernatant of APEC strain using ultracentrifugation. After purification by density gradient centrifugation, the vast majority of particles were detected in fractions 3-5 using NTA (Fig. 1c). The densities of these fractions range from 1.127 to $1.175 \mathrm{~g} /$ 


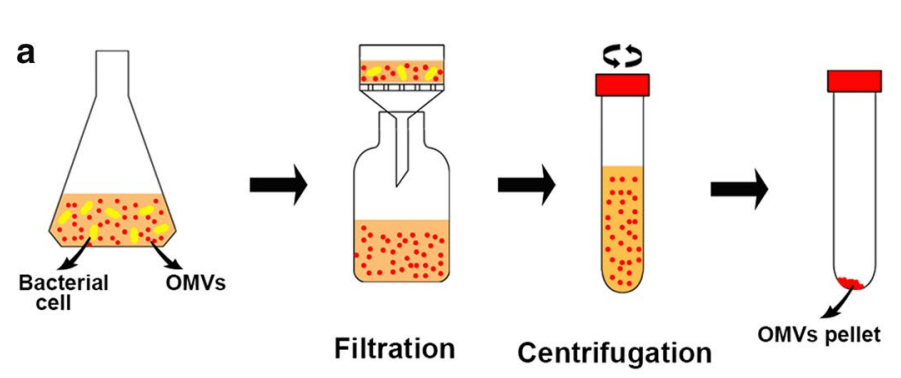

b

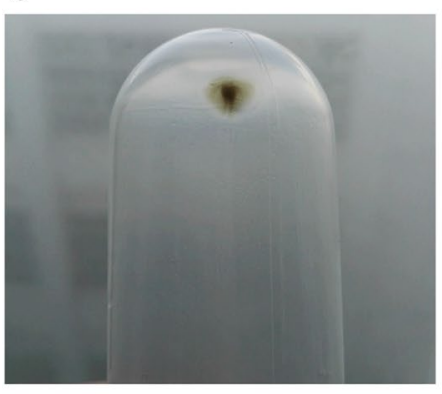

e

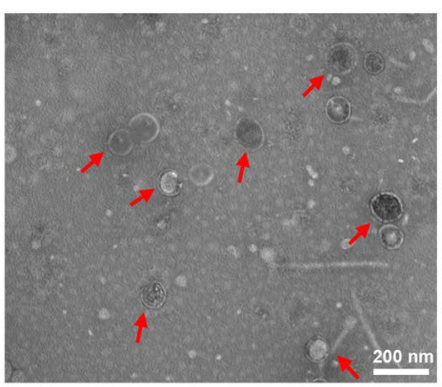

c

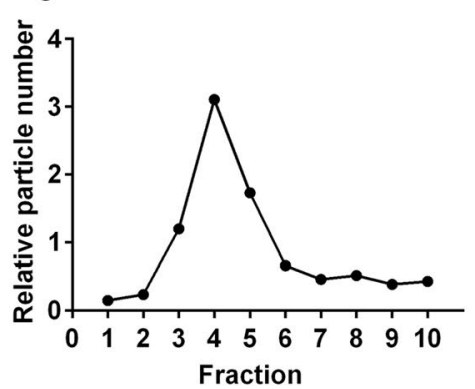

$1.079 \quad$ OptiPrep density $(\mathrm{g} / \mathrm{mL}) \mathbf{1 . 2 9 5}$

f

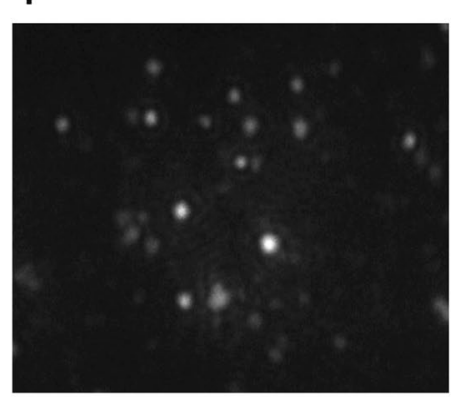

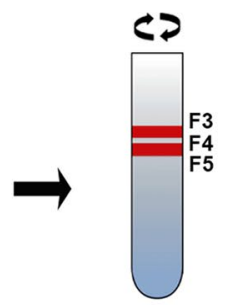

OptiPrep density

gradient

d

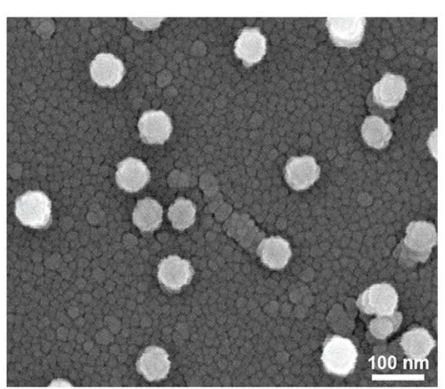

g $E 7$

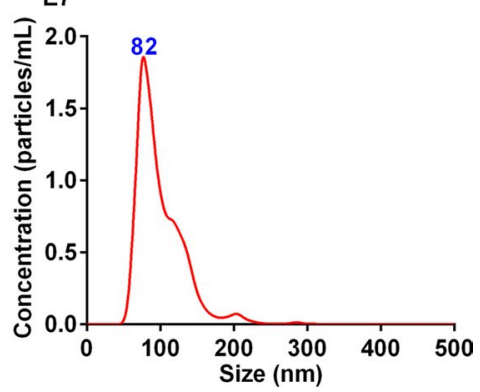

Fig. 1 Preparation and visualization of OMVs derived from avian pathogenic Escherichia coli. a Isolation and purification protocols of bacterial OMVs. b Native OMVs were isolated and pelleted by ultracentrifugation. c OMVs were purified by Optiprep density gradient ultracentrifugation. The particle numbers of the resulting fractions $(1-10)$ were detected by nanoparticle tracking analysis (NTA). Purified MOMV $_{S}$ were visualized using scanning electron microscope $(\mathbf{d})$ and transmission electron microscopy (e) after negative staining. $\mathbf{f}$ Representative frame was captured from the MOMVs NanoSight videos. $\mathbf{g}$ Size distribution and concentration of these vesicles was determined by NTA

$\mathrm{mL}$, which is consistent with the previously reported density of bacterial OMVs [26]. Purified MOMVs were made with each purified OMVs from three APEC strains and observed by scanning electron microscopy (Fig. 1d) and transmission electron microscopy (Fig. 1e). The results show that the APEC strains abundantly produced the spherical vesicles with a morphology of bilayer membrane. Typical results from NTA characterization of MOMVs, as shown in Fig. If and g, reveal that the sizes of the majority of MOMVs range from 50 to $200 \mathrm{~nm}$ and peak at $82 \mathrm{~nm}$, which is in accordance with the previously determined sizes of bacterial OMVs [23].

\section{Proteomic analysis of MOMVs}

SDS-PAGE analyses of proteins from MOMVs and whole cell lysates are shown in Fig. 2a. Several OMPs (e.g., OmpA, OmpC and OmpF) and lipoproteins were found in the lane of the MOMVs samples according to the molecular weight. The protein composition was confirmed by the subsequent LC-MS/MS analysis. By proteomic analysis, 159 proteins were identified, and their subcellular localization are shown in Fig. 2b. Of these identified proteins, 68 (42.8\%), 56 (35.2\%), 19 (12.0\%) and $11(6.9 \%)$ were derived from outer membrane, cytoplasm, periplasm and inner membrane, respectively. The 


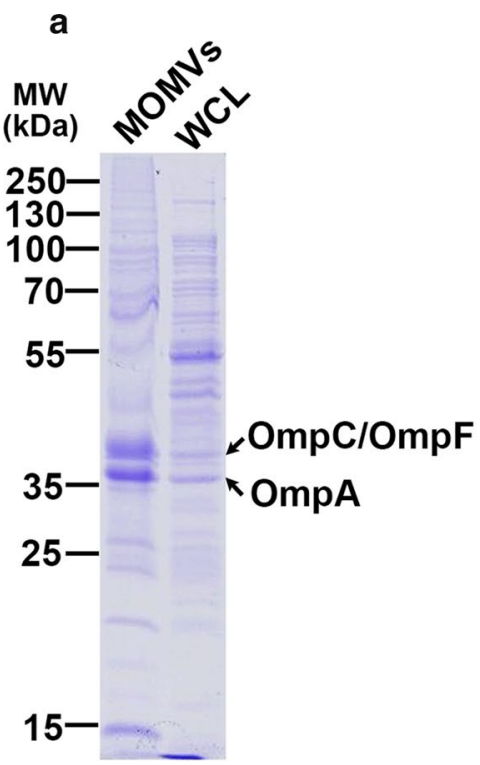

b

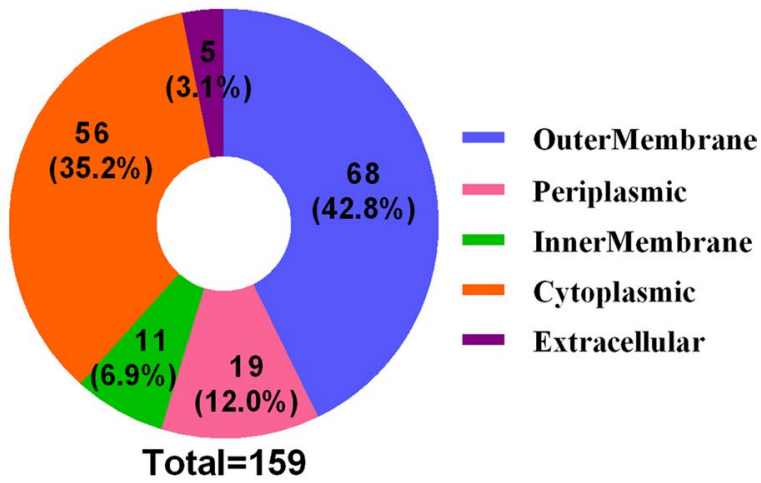

Fig. 2 Proteomic analysis of MOMVs derived from APEC strains. a Protein profiles of MOMVs and whole-cell lysates (WCL) from three APEC strains analyzed by Coomassie Brilliant Blue-stained SDS-PAGE. Arrows represent the two major vesicular protein bands. b Proteins of MOMVs identified by LC-MS/MS were classified according to their subcellular localizations

20 most abundant proteins found in MOMVs, their subcellular localization and biological functions are shown in Table 1. Many OMPs, such as OmpA, OmpC, OmpX and OmpW, and some outer membrane lipoproteins were highly enriched, suggesting that MOMVs and outer membrane of their parental bacteria have high similarity in function and structure. Furthermore, the abundance of $60 \mathrm{kDa}$ chaperonin, Fe $(3+)$ dicitrate transport protein, LPS-assembly protein and ferrichrome outer membrane transporter indicated functions of the MOMVs involved in protein processing, virulence, signaling, etc. These multiple immunogenic proteins found in MOMVs suggested that MOMVs had the potential to be an effective vaccine candidate.

\section{MOMVs induced innate immune responses in vitro}

To evaluate their potential immunogenicity, we first investigated whether chicken macrophages could recognize and respond to MOMVs in vitro. Confocal microscopy analysis showed that the red signals were found in the cytoplasm of chicken HD11 macrophages when these cells were treated with the DiI-labeled MOMVs, revealing that these vesicles were taken up by macrophages (Fig. 3a). Furthermore, HD11 cells stimulated with MOMVs secreted higher production of immunomodulatory cytokines in a dose-dependent manner, including IL-6 (Th17-polarizing cytokines), TNF- $\alpha$ (pro-inflammatory cytokines) and IL-12 (Th1-polarizing cytokines) (Fig. 3b). These findings indicated that MOMVs were effectively internalized by chicken macrophages and provoked the innate immune cells to produce cytokines that are able to mediate adaptive immune responses.

\section{Immunization with MOMVs provoked specific humoral} immune responses

To further test the immunogenicity of MOMVs, we also evaluated the effect of MOMVs vaccination on the induction of specific IgG titers against these three OMVs in vivo. The production of specific IgG was determined for the first, second and third immunization. We found that immunization with MOMVs significantly improved the production of specific IgG against these three OMVs (Fig. $4 \mathrm{a}-\mathrm{c}$ ) in both dose-dependent and frequencydependent manners. After the final immunization, the specific IgG production in the group immunized with $50 \mu \mathrm{g}$ of MOMVs was not significantly different from that in the group immunized with $100 \mu \mathrm{g}$ of MOMVs This result implied that immunization with $50 \mu \mathrm{g}$ of MOMVs might be sufficient to induce a strong specific antibody response. Together, these results indicated that vaccination with MOMVs effectively induced specific antibody responses against each OMVs antigen.

\section{Immunization with MOMVs induced specific cellular immune responses}

Next, we evaluated the effect of MOMVs immunization on the induction of cellular immune responses. One week after the final immunization, we determined 
Table 1 Top 20 most abundant proteins identified in MOMVs

\begin{tabular}{|c|c|c|c|c|c|c|c|}
\hline Rank & Protein accession & Gene name & Protein annotation & Subcellular localization & Biological function & MW (kDa) & Intensity \\
\hline 1 & P0A910 & ompA & Outer membrane protein $A$ & Outer membrane & $\begin{array}{l}\text { Cell wall/membrane/enve- } \\
\text { lope biogenesis }\end{array}$ & 37.2 & $7.57 E+11$ \\
\hline 2 & P69776 & Ipp & $\begin{array}{l}\text { Major outer membrane } \\
\text { prolipoprotein Lpp }\end{array}$ & Outer membrane & $\begin{array}{l}\text { Cell wall/membrane/enve- } \\
\text { lope biogenesis }\end{array}$ & 8.3234 & $6.39 \mathrm{E}+11$ \\
\hline 3 & P06996 & ompC & Outer membrane protein $C$ & Outer membrane & $\begin{array}{l}\text { Cell wall/membrane/enve- } \\
\text { lope biogenesis }\end{array}$ & 40.368 & $4.83 \mathrm{E}+11$ \\
\hline 4 & P0A903 & bamc & $\begin{array}{l}\text { Outer membrane protein } \\
\text { assembly factor BamC }\end{array}$ & Outer membrane & $\begin{array}{l}\text { Cell wall/membrane/enve- } \\
\text { lope biogenesis }\end{array}$ & 36.842 & $3.39 \mathrm{E}+11$ \\
\hline 5 & P0A6F5 & groL & 60 kDa chaperonin & Cytoplasmic & $\begin{array}{l}\text { Posttranslational modifica- } \\
\text { tion, protein turnover, } \\
\text { chaperones }\end{array}$ & 57.328 & $3.07 E+11$ \\
\hline 6 & P0A905 & slyB & $\begin{array}{l}\text { Outer membrane lipopro- } \\
\text { tein SlyB }\end{array}$ & Outer membrane & $\begin{array}{l}\text { Cell wall/membrane/enve- } \\
\text { lope biogenesis }\end{array}$ & 15.601 & $1.87 E+11$ \\
\hline 7 & P0A917 & ompX & Outer membrane protein $X$ & Outer membrane & $\begin{array}{l}\text { Cell wall/membrane/enve- } \\
\text { lope biogenesis }\end{array}$ & 18.602 & $9.60 \mathrm{E}+10$ \\
\hline 8 & P0A908 & mipA & MltA-interacting protein & Outer membrane & $\begin{array}{l}\text { Cell wall/membrane/enve- } \\
\text { lope biogenesis }\end{array}$ & 27.831 & $8.14 \mathrm{E}+10$ \\
\hline 9 & P61320 & lolB & $\begin{array}{l}\text { Outer-membrane lipopro- } \\
\text { tein LolB }\end{array}$ & Outer membrane & $\begin{array}{l}\text { Cell wall/membrane/enve- } \\
\text { lope biogenesis }\end{array}$ & 23.55 & $6.45 E+10$ \\
\hline 10 & P0A915 & ompW & $\begin{array}{l}\text { Outer membrane protein } \\
\text { W }\end{array}$ & Outer membrane & $\begin{array}{l}\text { Cell wall/membrane/enve- } \\
\text { lope biogenesis }\end{array}$ & 22.928 & $5.63 \mathrm{E}+09$ \\
\hline 11 & P06959 & aceF & $\begin{array}{l}\text { Dihydrolipoyllysine- } \\
\text { residue acetyltransferase } \\
\text { component of pyruvate } \\
\text { dehydrogenase complex }\end{array}$ & Cytoplasmic & $\begin{array}{l}\text { Energy production and } \\
\text { conversion }\end{array}$ & 66.095 & $5.45 E+09$ \\
\hline 12 & P09394 & glpQ & $\begin{array}{l}\text { Glycerophosphodiester } \\
\text { phosphodiesterase }\end{array}$ & Periplasmic & $\begin{array}{l}\text { Energy production and } \\
\text { conversion }\end{array}$ & 40.843 & 4.41E+09 \\
\hline 13 & P13036 & fecA & $\begin{array}{l}\text { Fe }(3+) \text { dicitrate transport } \\
\text { protein FecA }\end{array}$ & Outer membrane & $\begin{array}{l}\text { Inorganic ion transport } \\
\text { and metabolism }\end{array}$ & 85.321 & $4.02 \mathrm{E}+09$ \\
\hline 14 & P0A940 & bamA & $\begin{array}{l}\text { Outer membrane protein } \\
\text { assembly factor BamA }\end{array}$ & Outer membrane & $\begin{array}{l}\text { Cell wall/membrane/enve- } \\
\text { lope biogenesis }\end{array}$ & 90.552 & $2.09 \mathrm{E}+09$ \\
\hline 15 & P31554 & IptD & LPS-assembly protein LptD & Outer membrane & $\begin{array}{l}\text { Cell wall/membrane/enve- } \\
\text { lope biogenesis }\end{array}$ & 89.67 & $9.78 \mathrm{E}+08$ \\
\hline 16 & P06971 & fhuA & $\begin{array}{l}\text { Ferrichrome outer mem- } \\
\text { brane transporter/phage } \\
\text { receptor }\end{array}$ & Outer membrane & $\begin{array}{l}\text { Inorganic ion transport } \\
\text { and metabolism }\end{array}$ & 82.181 & 7.20E+08 \\
\hline 17 & P21420 & $\mathrm{nmpC}$ & $\begin{array}{l}\text { Putative outer membrane } \\
\text { porin protein } \mathrm{NmpC}\end{array}$ & Outer membrane & $\begin{array}{l}\text { Cell wall/membrane/enve- } \\
\text { lope biogenesis }\end{array}$ & 40.302 & $7.03 E+08$ \\
\hline 18 & POAFG8 & aceE & $\begin{array}{l}\text { Pyruvate dehydrogenase } \\
\text { E1 component }\end{array}$ & Cytoplasmic & $\begin{array}{l}\text { Energy production and } \\
\text { conversion }\end{array}$ & 99.667 & $6.63 E+08$ \\
\hline 19 & P21513 & rne & Ribonuclease E & Cytoplasmic & $\begin{array}{l}\text { Translation, ribosomal } \\
\text { structure and biogenesis }\end{array}$ & 118.2 & $6.48 \mathrm{E}+08$ \\
\hline 20 & P00968 & $\operatorname{carB}$ & $\begin{array}{l}\text { Carbamoyl-phosphate } \\
\text { synthase subunit beta }\end{array}$ & Periplasmic & $\begin{array}{l}\text { Membrane biogenesis/ } \\
\text { synthesize carbamoyl } \\
\text { phosphate }\end{array}$ & 117.842 & $4.28 \mathrm{E}+08$ \\
\hline
\end{tabular}

MOMVs represents multi-serogroup outer membrane vesicles derived from avian pathogenic Escherichia coli

the expression levels of major histocompatibility complex class II $\beta$ gene (MHC-II $\beta$ ) and T cell-mediated immune genes, including $\mathrm{T}$ helper (Th) 1 type cytokine (IFN- $\gamma$ ), Th2 type cytokine (IL-4), and regulatory T cell cytokine (IL-10) in spleen tissues. The results showed that IFN- $\gamma$ (Fig. 5a) and IL-17 (Fig. 5c) were obviously activated in all MOMVs-immunized groups. However, the expression level of IL-4 gene (Fig. 5b) was similar in the MOMVs- and PBS-immunized groups. Moreover, the expression level of IL-10 (Fig. 5d), the major anti-inflammatory cytokine, was higher in the MOMVs-immunized groups compared with the control. These results indicated that both anti-inflammatory and pro-inflammatory cytokine genes were activated simultaneously in the MOMVs-immunized groups to balance the inflammatory responses. Furthermore, the higher expression level of 


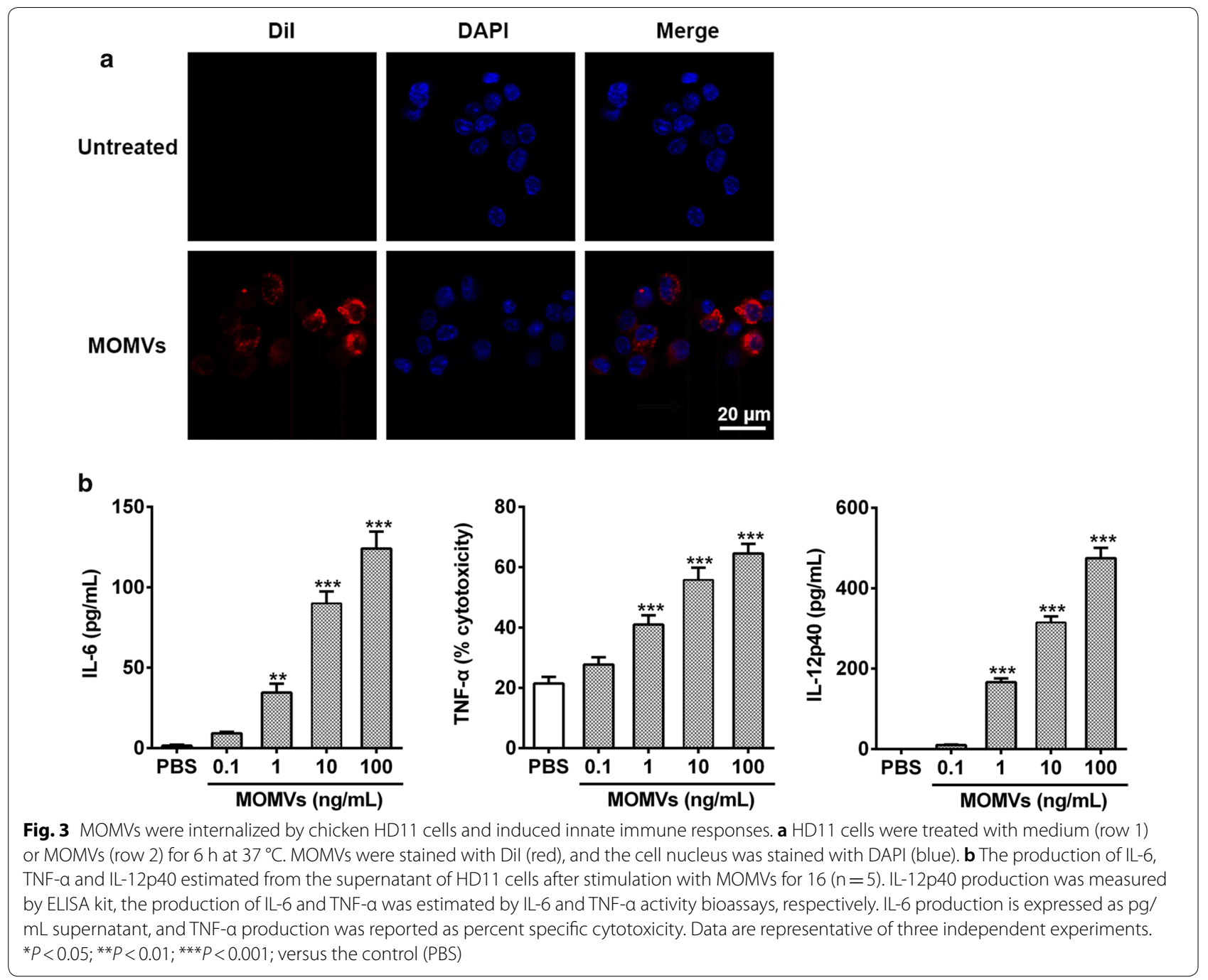

MHC-II $\beta$ (Fig. 5e), expressed in antigen-presenting cells (APCs), was also observed in the MOMVs-immunized groups. This finding suggested that MOMVs could be recognized by APCs, which in turn activate T cells. Collectively, these results suggested that immunization with MOMVs was able to activate APCs and elicit Th1- and Th17-cell responses.

\section{The immunization effect of MOMVs on cross-protection against APEC infections}

We first established chicken models of APEC infections by intratracheal injection of various doses of each APEC strain (Additional file 1: Fig. S1). The LD of APEC $\mathrm{O} 1, \mathrm{O} 2$ and $\mathrm{O} 78$ in this model was $5 \times 10^{8}, 1 \times 10^{9}$ and $5 \times 10^{8} \mathrm{CFU}$, respectively. After vaccination with various doses of the MOMVs every week for 3 weeks (Fig. 6a, upper panel), the chickens were infected with the LD of each APEC strain 1 week after the last vaccination, respectively. During a 10-day observation phase, all of the PBS-immunized birds died 7 days after challenges of APEC O1, O2 and O78, respectively. However, the survival rate of MOMVs-immunized birds was obviously improved in a dose-dependent manner within a certain dose range. Immunization with $50 \mu \mathrm{g}$ of MOMVs accounted for $100 \%, 90 \%$ and $100 \%$ of the protective efficacy against infection of APEC O1, O2 and O78, respectively (Fig. 6a, below panel). However, the protective efficacy was not improved when the immunization dose of MOMVs was further increased to $100 \mu \mathrm{g}$. To investigate whether different doses of MOMVs cause any adverse effect on chickens, we examined the effect of MOMVs immunization on growth performance and inflammation-related cells (Additional file 2: Fig. S2). Immunization with 10 and $50 \mu \mathrm{g}$ of MOMVs had no significant effects on growth performance and the number of blood inflammation-related cells during the 
APEC 01

Number of immunization
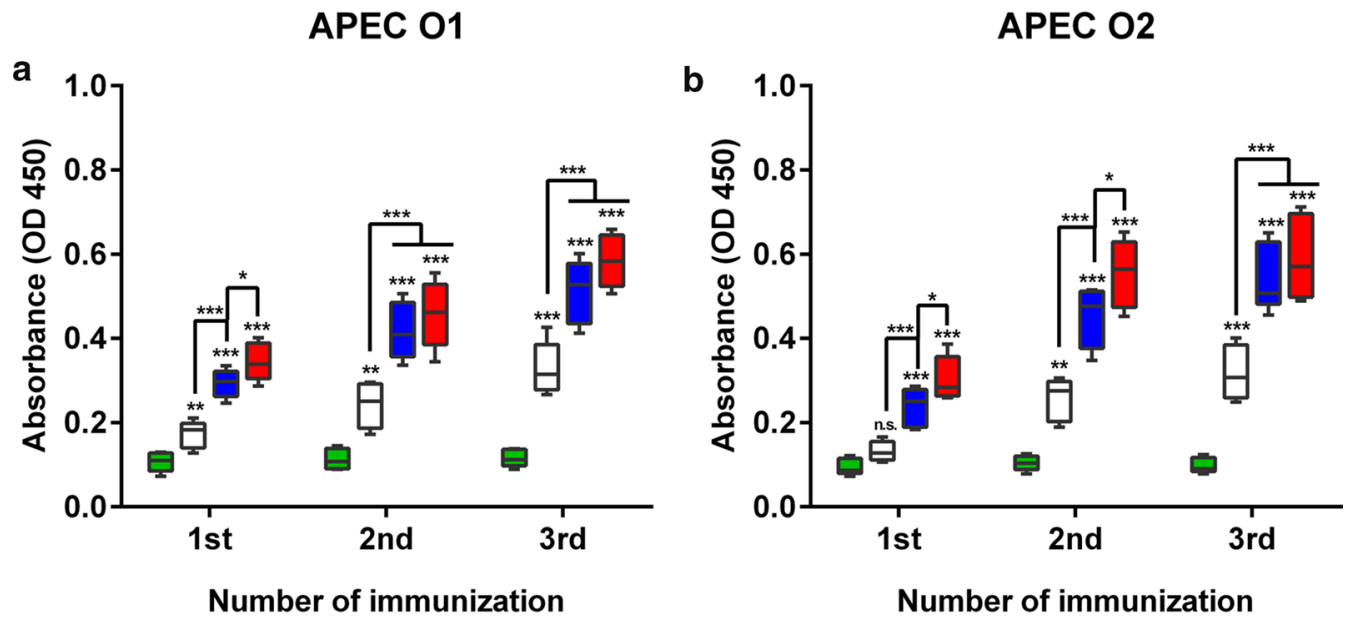

APEC 078

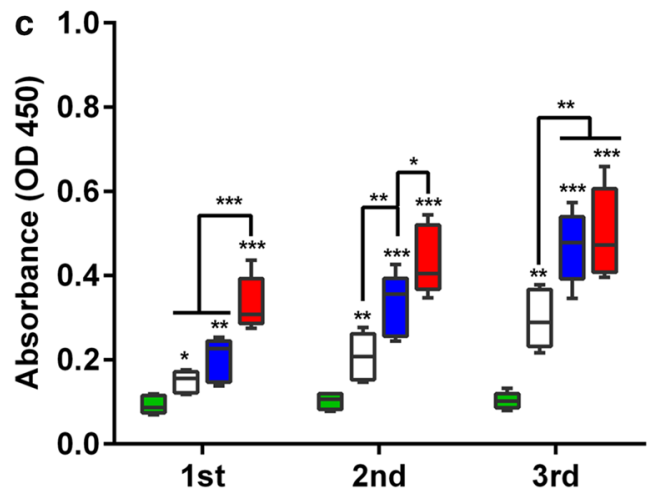

PBS

MOMVs $(10 \mu \mathrm{g})$

MOMVs $(50 \mu \mathrm{g})$

MOMVs $(100 \mu \mathrm{g})$

Number of immunization

Fig. 4 Immunization with MOMVs provoked specific antibody responses against each OMVs of these three OMVs. The production of specific lgG in MOMVs- and PBS-immunized sera was determined against each OMVs, respectively: a OMVs derived from APEC O1; b OMVs derived from APEC O2 ser; c OMVs derived from APEC 078. Sera were sampled from each group $(n=5) 7$ days after the first, second and third immunization. The production of specific lgG was measured by ELISA. Data are representative of two independent experiments. ${ }^{*} P<0.05$; ${ }^{* *} P<0.01 ;{ }^{* *} P<0.001$; versus the control (PBS)

immunization period of 7-28 days. However, immunization with $100 \mu \mathrm{g}$ of MOMVs significantly reduced growth performance and the number of platelets and increased the number of white blood cells, indicating that an occurrence of inflammation in body. Together, it was reasonable to choose $50 \mu \mathrm{g}$ as the final vaccination dosage in the current study. Next, we evaluated whether MOMVs immunization had a long-term protection against APEC infections. Five weeks after the final immunization (day 56), chickens in the group immunized with $50 \mu \mathrm{g}$ of MOMVs were infected with the $2 \times \mathrm{LD}$ of each APEC strain (Fig. 6b). The survival rate of the MOMVs-immunized group was significantly higher than that of the PBSimmunized group after infection of each APEC strain. Collectively, these results suggested that immunization with $50 \mu \mathrm{g}$ of MOMVs can provide effective cross-protection against infections induced by these three APEC strains.

\section{MOMVs-mediated protective immunity agreed with the reduction of bacterial burden and inflammatory cytokine production}

In order to study the possible mechanism of MOMVsmediated protective immunity, we first examined the bacterial burdens in liver and lung tissues from chickens immunized with MOMVs $(50 \mu \mathrm{g})$ or PBS at indicated time after APEC infection. As shown in Fig. 7a, immunization with MOMVs significantly reduced the counts of APEC strains in both liver and lung tissues, suggesting an effective clearance of these pathogens at $24 \mathrm{~h}$ 

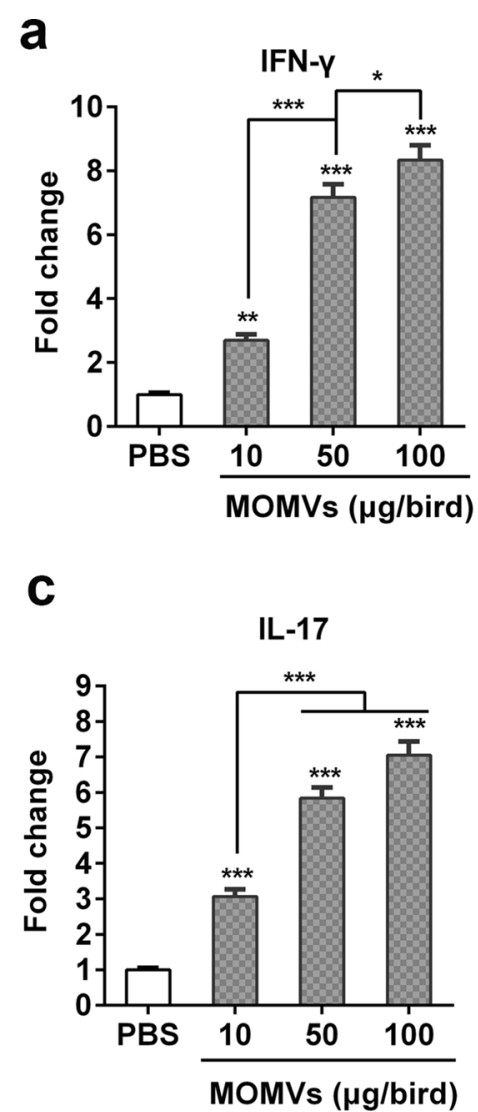

b

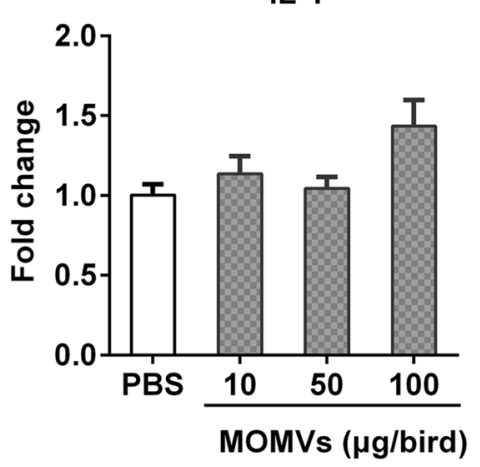

d

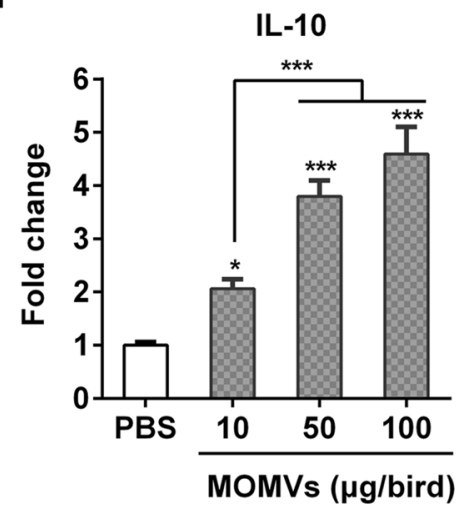

$\mathbf{e}$

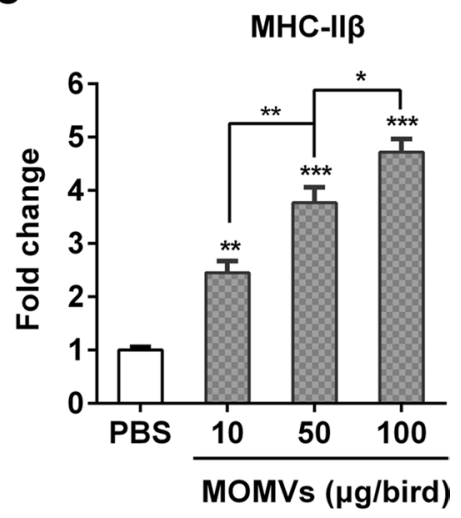

Fig. 5 Immunization with MOMVs elicited cellular responses in spleen. One weeks after the final immunization, spleen tissues of chickens $(n=5)$ were sampled for the evaluation of immune gene expression. The qRT-PCR analysis was performed for the expression levels of cytokine genes: IFN- $\gamma$ (a), IL-4 (b), IL-17 (c), IL-10 (d) and MHC-1I $\mathrm{g}$ (e). Data are representative of two independent experiments. ${ }^{*} P<0.05$; ${ }^{* *} P<0.01$; ${ }^{* * *} P<0.001$; versus the control (PBS)

after challenge. These findings can be confirmed by the results of bacterial CFU counting in liver tissue (Additional file 3: Fig. S3). In contrast, a large number of bacteria were found in these two tissues from the PBSimmunized chickens. Then, we determined the levels of major pro-inflammatory cytokines (IL- 6 and TNF- $\alpha$ ) in the serum from MOMVs- and PBS-immunized chickens sampled at $24 \mathrm{~h}$ after the last immunization and $24 \mathrm{~h}$ after the bacterial challenge. Similar levels of these pro-inflammatory cytokines were observed between MOMVs- and PBS-immunized groups at $24 \mathrm{~h}$ after the last immunization, indicating again that immunization with $50 \mu \mathrm{g}$ of MOMVs would not induce inflammation (Fig. 7b). Although pathogen challenge significantly improved the production of serum IL- 6 and TNF- $\alpha$ in both the MOMVs-immunized group and the control, the levels of these two cytokines were significantly lower in the MOMVs-immunized group. These findings demonstrated that MOMVs mediated protective immunity via reducing bacterial burdens and pro-inflammatory cytokine levels.

\section{Both vesicular LPS and proteins were key factors} in MOMVs-mediated protection

Studies have shown that LPS and OMPs enriched in OMVs are known to be potent immunostimulators [2830]. In the present study, proteomic analysis (Fig. 2) and LAL assay (Fig. 8a) also revealed the abundance of LPS and OMPs in MOMVs. We further investigated the roles of vesicular proteins and LPS in MOMVs-induced protection. MOMVs were treated with polymyxin B (PMB_MOMVs) and proteinase K (PK_MOMVs) to remove vesicular LPS and proteins, respectively. The effectiveness of the treatments was confirmed by LAL assay (Fig. 8a) and SDS-PAGE analysis (Fig. 8b). When chickens were immunized with PMB_MOMVs $(50 \mu \mathrm{g})$ for 3 weeks, no obvious induction of anti-LPS IgG was observed in the PMB_MOMVs group (Fig. 8c). Similarly, no significant induction of anti-MOMPs IgG in the PK_MOMVs group when chickens were immunized with PK_MOMVs $(50 \mu \mathrm{g})$ (Fig. 8d). These findings indicated both vesicular LPS and proteins 


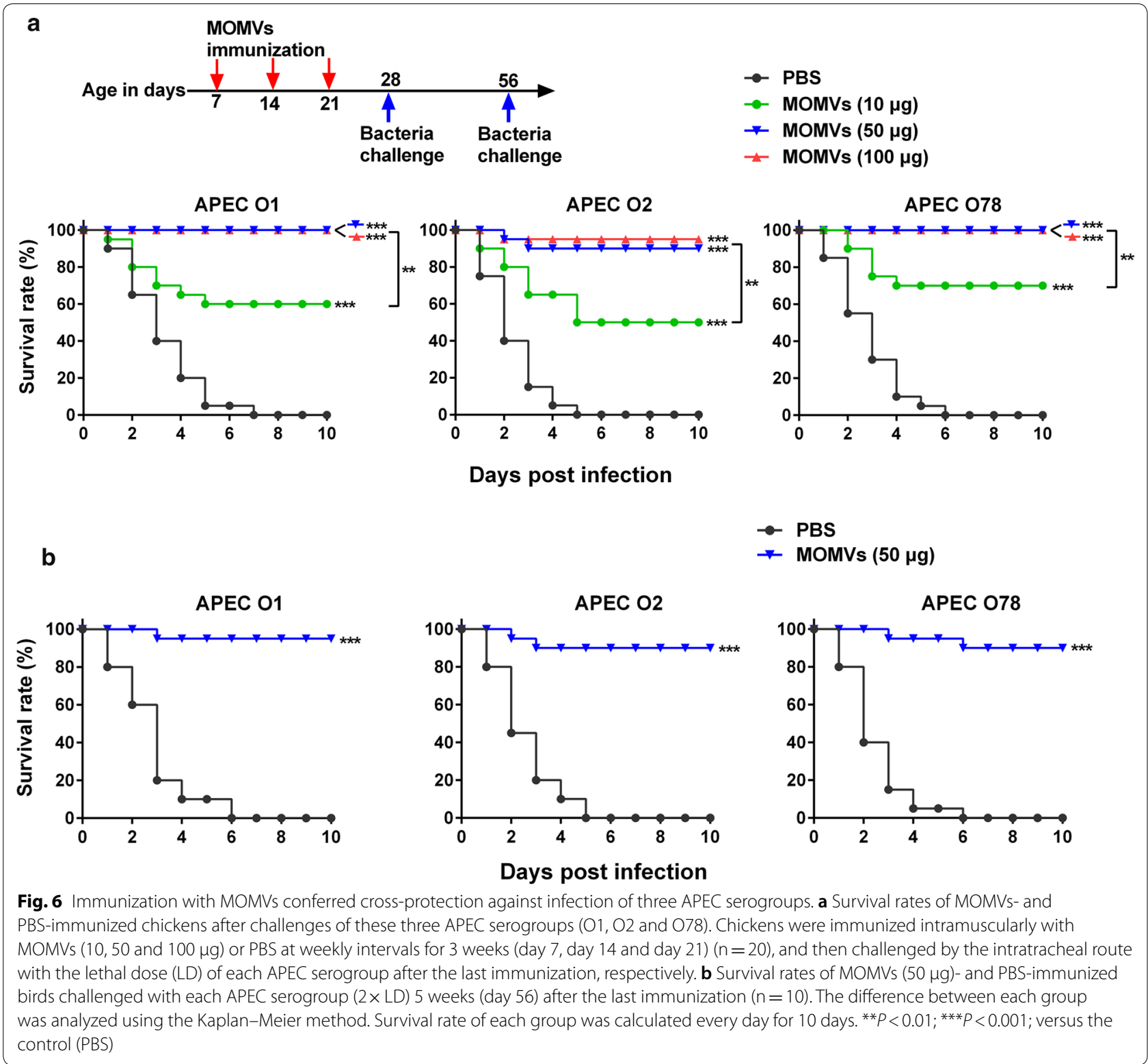

were essential for IgG immune responses. Finally, we evaluated the protection effect of immunization with PMB_MOMVs $(50 \mu \mathrm{g})$ and PK_MOMVs $(50 \mu \mathrm{g})$. As shown in Fig. 8e, when chickens were infected with the APEC strains, survival rate of both PMB_MOMVs and PK_MOMVs group was significantly higher than that of the PBS control group, whereas significantly lower than that of the MOMVs group. Moreover, the survival rate of PK_MOMVs group was obviously lower than that of the PMB_MOMVs group. These findings indicated both vesicular proteins and LPS were crucial in
MOMVs-mediated protection with vesicular proteins showing a higher protective efficiency.

\section{Discussion}

Despite the discovery of OMVs secreted by Gram-negative bacteria in the 1960s, the composition and function of OMVs have not been studied until the last decade [31, 32]. Therefore, the applications of bacterial OMVs research in many fields are still in its infancy. Recently, OMVs have attracted more and more attentions as new and feasible candidates for the development of next generation vaccines [13]. Many researchers have been 


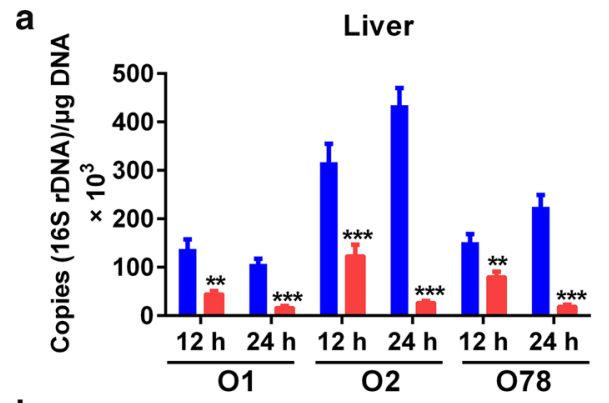

b

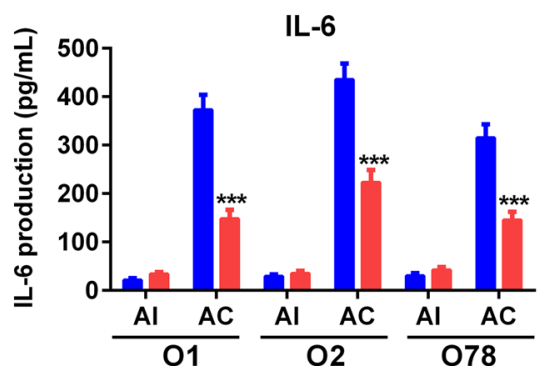

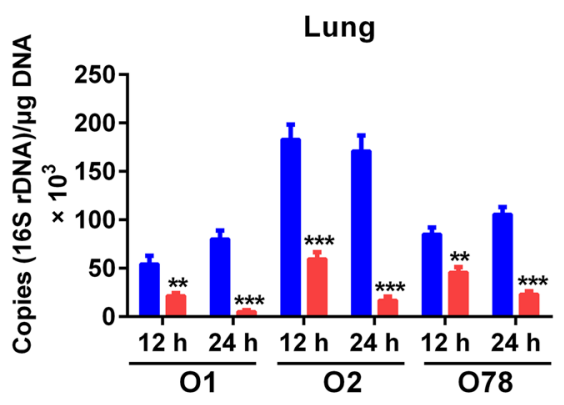
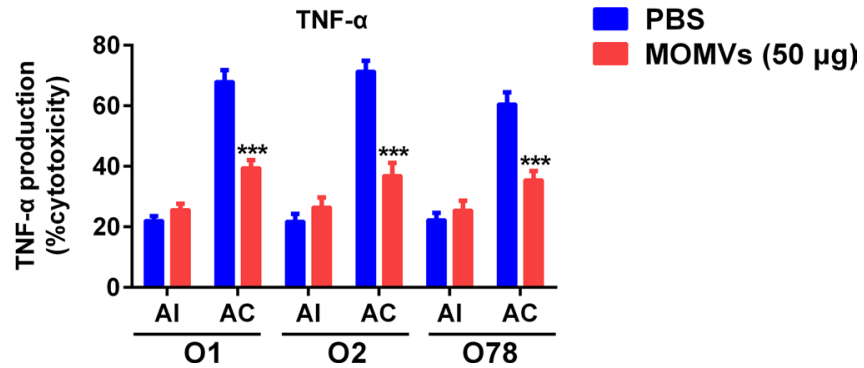

Fig. $7 \mathrm{MOMVs}$-mediated protective immunity agreed with the reduction of bacterial burden and inflammatory cytokine production. a Bacterial burdens in liver and lung of chickens immunized with MOMVs $(50 \mu \mathrm{g})$ and PBS at 12 and $24 \mathrm{~h}$ after challenge with the lethal dose of each APEC serogroup (O1, $\mathrm{O} 2$ and O78). Bacterial burden was estimated by qRT-PCR using specific primers and probe derived from 165 rDNA sequences of E. coli $(n=5)$. $\mathbf{b}$ The production of pro-inflammatory cytokines (IL-6 and TNF-a) in serum from MOMVs $(50 \mu \mathrm{g})$ - and PBS-immunized chickens at day 22 ( $24 \mathrm{~h}$ after the last immunization, Al) and day 29 ( $24 \mathrm{~h}$ after challenge of each APEC serogroup, AC) $(\mathrm{n}=5)$. Data are representative of three independent experiments. ${ }^{* *} P<0.01 ;{ }^{* *} P<0.001$; versus the control (PBS)

trying to develop effective vaccines against APEC infection. To date, as the diversity of APEC serogroups poses challenges for the development of viable vaccines, there are currently no licensed vaccine candidates to prevent APEC infection in poultry farms [9]. To overcome this obstacle, we prepared OMVs from three APEC strains, based on which, a novel multi-serogroup vaccine candidate with multivalent OMVs immunogen was designed, and then, the protective immunity induced by the MOMVs in chickens was investigated. The results demonstrated that the MOMVs could effectively protect chickens against lethal infections induced by multi-serogroup APEC strains. Both innate and adaptive immune responses activated by MOMVs were involved in the cross-protection.

In order to develop an ideal vaccine against APEC infection, several factors have to be taken into account, including the method of vaccination, the use of the adjuvant, the safety and stability and the broad protection [9]. Since mass vaccination is required to immunize a large number of chickens, we focused on vaccination via intramuscular injection, which is the most common route of chicken immunization. The use of adjuvants is an important factor affecting the protection efficacy of vaccines. Vaccine adjuvants play a very important role in the quality and intensity of immune responses [33]. Many
Toll-like receptors (TLR) agonists are commonly used as immune adjuvants to enhance antigen-specific immune responses [34]. OMV $\mathrm{OPEC}_{\mathrm{APE}}$ contains many components found in the outer membrane of their parental bacteria, which are ligands for TLR, thus making $\mathrm{OMV}_{\mathrm{APEC}}$ itself a good adjuvant $[23,35]$. In the present study, the good immunogenicity of MOMVs was demonstrated by their roles in inducing innate and adaptive immune responses. Although OMVs carry some components of virulence factors, numerous studies have shown the safety of lowdose OMVs $[15,17,22]$, which is also confirmed in our experiments. The unique structural characteristics with nano-scale vesicles and spherical lipid-bilayers endow OMVs as a biocompatible and stable vaccine carrier [36]. Moreover, an ideal APEC vaccine must be capable of eliciting cross-protection to against various APEC serogroups. OMVs from a single serogroup can induce certain cross-protection because they contain a wide variety of conserved immunogenic components, including a large number of OMPs and pathogen-related molecular patterns [11, 14, 37]. Recent study has showed that immunization with OMVs produced by APEC O78 can protect chickens from APEC O78 infection [27]. However, a single serogroup OMVs may be difficult to induce effective protection against APEC multi-serogroups. To improve the protective efficacy, we developed the 

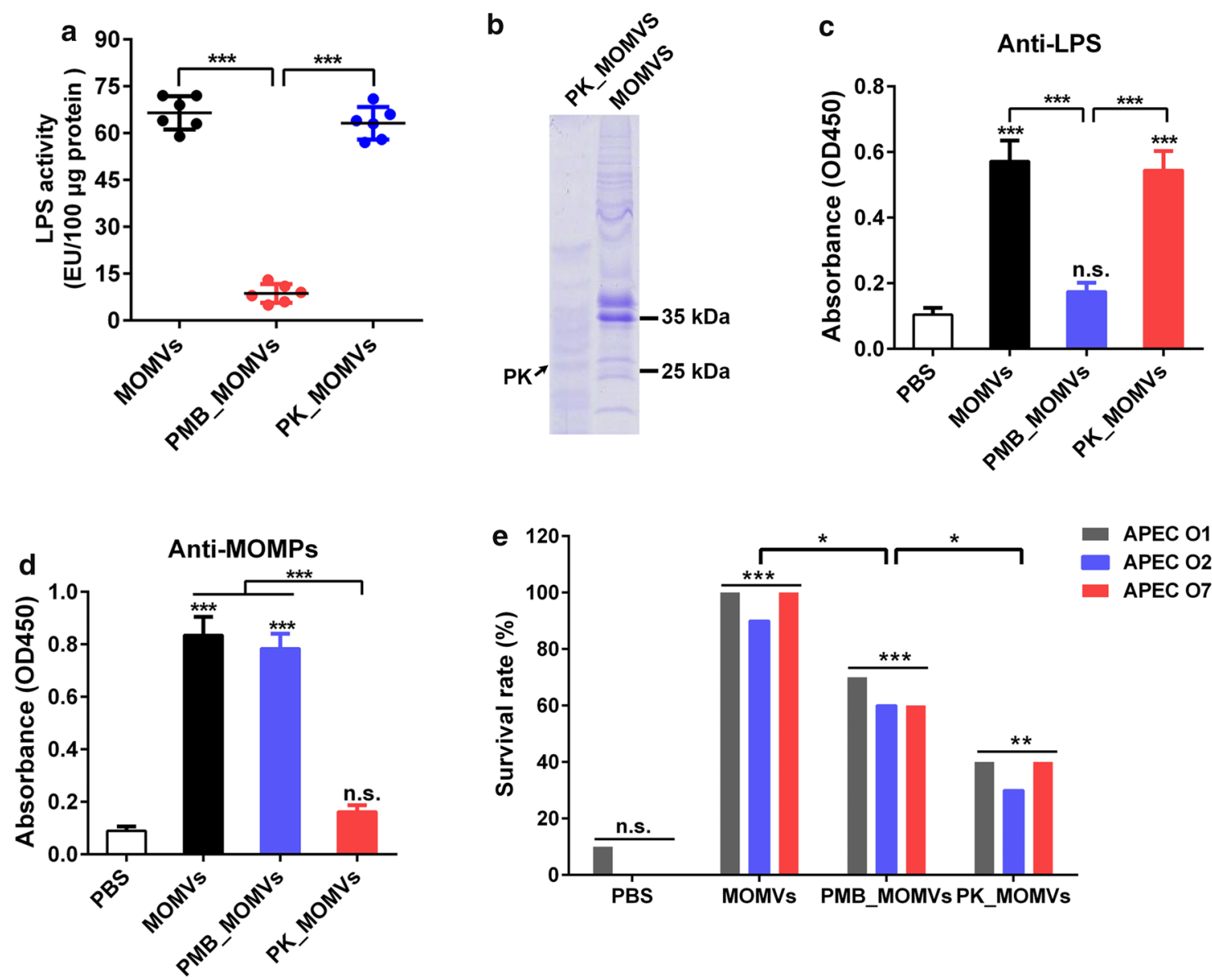

Fig. 8 Evaluation of the roles of vesicular proteins and LPS in MOMVs-mediated protection. a Determination of LPS contents in MOMVs, polymyxin B-treated MOMVs (PMB_MOMVs) and proteinase K-treated MOMVs (PK_MOMVs) by LAL assay. b Coomassie Brilliant Blue-stained SDS-PAGE analysis detected the protein profiles of MOMVs and PK_MOMVs. The IgG titers of anti-OMPs (c) and anti-LPS $(\mathbf{d})$ in sera from chickens $(n=5)$ immunized with PBS, MOMVs, PMB_MOMVs and PK_MOMVs. e Survival rates of MOMVs- $(50 \mu \mathrm{g})$, PMB_MOMVs- $(50 \mu \mathrm{g})$, PK_MOMVs-(50 $\mu \mathrm{g})$ and PBS-immunized chickens $(n=10)$ after the lethal infections of these three APEC serogroups $(01,02$ and $\mathrm{O} 78) .{ }^{*} P<0.05 ;{ }^{* *} P<0.01$; ${ }^{* *} P<0.001$; n.S., not significant; versus the control (PBS)

MOMVs vaccine with three different OMVs from APEC serogroups (O1, O2 and O78) that frequently cause APEC infection. The broad and long-term effect of the MOMVs also was verified in our animal experiments.

In addition to the improved survival rate, the treatment of MOMVs led to significant pathogen clearance and reduction of pro-inflammatory cytokines, confirming the effective protection of MOMVs. Many studies have been published to explain the mechanism of MOMVs in the treatment of pathogenic E. coli infection. Several studies revealed the importance of innate immune cells, such as neutrophils and macrophages [38]. Many studies demonstrated that specific antibody responses played the dominant role [26, 39, 40], while some reports emphasized the importance of the cellular immune response, especially Th1- and Th17-mediated immune responses [22]. In fact, both antigen-nonspecific innate immunity and antigen-specific adaptive immunity cooperated in host defense against pathogen invasion. Macrophages play a connecting role between innate and adaptive immunity by presenting antigen and initiating antigen-specific immune responses via the secreted cytokines [41]. We found that MOMVs were internalized by chicken macrophages and these cells were provoked to secrete Th1- and Th17-polarizing cytokines (IL-12 and IL-6) in vitro. Consistent with our findings, previous studies have revealed that bacterial OMVs can activate innate immune cells, such as dendritic cells and macrophages, to produce immunoregulatory cytokines and co-stimulatory molecules [17, 22]. Besides, MHCII molecules can deliver exogenous antigens to Th cells, triggering the activation of these cells and thus inducing adaptive immune responses [42]. After immunization with MOMVs, the expression of MHC-II $\beta$ was 
obviously elevated in the spleen of MOMVs-immunized birds, indicating that MOMVs were recognized by APCs, and antigen presentation was enhanced. Studies have shown that bacterial OMVs can induce specific antibodies and $\mathrm{T}$ cell immune responses [15-17, 22]. Our animal experiments also showed that MOMVs vaccination improved the production of specific antibodies and expression of Th1- and Th17-mediated immune genes (IFN- $\gamma$ and IL-17), indicating that both specific humoral and cellular immune responses were involved in the protective immunity induced by MOMVs. Due to the fact that vesicular proteins account for the highest proportion of the whole vesicle, and OMPs mainly contribute to the humoral immune response, we suspected that humoral immunity might be the major contributor to the MOMVs-mediated protection. The assumption was supported by the results that immunization with proteindeficient MOMVs dramatically reduced the survival rate of chickens infected by APEC strains. However, this does not necessarily mean that MOMVs work independently of cellular immunity, as APEC strains cause systemic infections, suggesting that cellular immunity may also play an important role in combating APEC infection [43]. Further studies are needed to determine the importance of humoral and cellular immune responses in MOMVsinduced protection.

Although the cross-protective effect of MOMVs was confirmed in the present study, it is difficult to clarify which components of the MOMVs are the main factors in immunoprotection [37]. Among the components of the OMVs, protein is the most important composition and mediates many functions of OMVs [11]. Proteomic studies have shown that OMPs are the most abundant molecules of total OMVs proteins, followed by cytoplasmic proteins, while periplasmic proteins and inner membrane proteins are the least. Most of these OMPs work as protective antigen and strongly provoke $\mathrm{T}$ cell-dependent humoral immune responses [28, 44]. The immunostimulation and protective effects of these proteins have been reported in various studies [28, 45, 46]. Several major OMPs, including OmpA, OmpC and OmpF, were identified in OMVs derived from APEC strains and other extraintestinal pathogenic E. coli $[46,47]$. In particular, OmpA and OmpC are ubiquitously found in all E. coli strains and have the ability to elicit protective immunity against pathogenic E. coli $[46,48]$. These conserved OMPs provide a certain level of cross-protection in various pathogenic E. coli strains. In addition, some T cellindependent antigens, such as LPS, are also responsible for the protective effects of OMVs [49]. Compared with OMPs, LPS only accounts for a small fraction of OMVs. As a $\mathrm{T}$ cell-independent antigen, LPS does not induce a high level of specific antibody response. Considering that vesicular proteins were more protective than LPS, OMPs might be the main composition that provoked cross-protection in MOMVs. However, it does not mean that those non-protein antigens are not essential for the protective effects of MOMVs. The combination of these protective antigens makes MOMVs broadly immunogenic. Further studies are needed to explore the exact components involved in the protective effects of MOMVs.

Compared with other traditional APEC vaccines developed over the years, the MOMVs-based vaccines were naturally obtained from bacteria and has many advantages. First, the MOMV-based vaccines are easy to obtain from bacteria. Second, because of the nanostructures and biocompatibility, MOMV vaccines have the potential for both immunoadjuvants and antigen delivery platforms [14]. Finally, and perhaps most importantly, MOMVbased vaccines may overcome the inefficiency of current APEC vaccines due to the broad immunogenicity of MOMVs derived from the diversity of both immunogens in individual $\mathrm{OMV}_{\mathrm{APEC}}$ and $\mathrm{OMV}_{\mathrm{APEC}}$ serogroups $[11,13]$. Although our work is encouraging, there are still many limitations. MOMVs vaccines may be more costly because of their time-consuming preparation and relatively low production, which is the limiting factor for the current large-scale application of OMVs vaccines. Besides, the window between effect and toxicity of MOMVs vaccines seems small. Further study is needed to reduce endotoxicity and production cost to make MOMVs vaccines become more convenient. Here we believe that the bionic OMVs solution, such as bacterial spheroplast-derived nanovesicles, may be a better choice [50]. This bacterial spheroplast-derived nanovesicles can be obtained from bacterial spheroplast using a series of extruded procedures, which contains relatively few components of cell-wall toxins and can be adopted in mass production. Therefore, these bionic OMVs vaccines may be both effective and lower side-effects.

\section{Conclusions}

To the best of our knowledge, the current APEC vaccines are more or less problematic in terms of poor safety and low efficacy. Here, we developed a multi-serogroup $\mathrm{OMV}_{\mathrm{APEC}}$ formulation to obtain broad-spectrum and long-term protection against multi-serogroup APEC infection. MOMVs vaccination provides broad protection via a combined humoral and cellular immunity. Although the detailed mechanisms of MOMVs-mediated cross-protection still need further investigation, our present work provides a new idea for the development of APEC vaccines against multi-serogroup APEC outbreaks. MOMVs vaccines could be used as candidates for next generation APEC vaccines due to their advantages, such as low toxicity and broad protection. 


\section{Methods}

\section{Animal and housing}

Experimental procedures and animal use were approved by the Northwest A\&F University Animal Care and Use Committee. Arbor Acres broiler chickens were purchased from Dacheng Poultry Industry Company (Xianyang, China) and raised in clean and sterilized rooms under standard conditions until they were 7 days old. Each room was provided with filtered, non-circulated air, and air pressure differences and strict sanitary conditions were maintained.

\section{Bacterial strains and preparation of MOMVs}

Three most common APEC strains that cause chicken colibacillosis, including O1, O2 and O78 serogroups, were obtained from China Veterinary Culture Collection Center. Bacterial OMVs were prepared from these three APEC strains using the protocol as described previously $[51,52]$. Briefly, the bacterial strain was grown in $\mathrm{LB}$ to the logarithmic phase at $37^{\circ} \mathrm{C}$ shaking at $180 \mathrm{rpm}$. Bacteria-free supernatant was collected by centrifugation (15 min, $12,000 g, 4{ }^{\circ} \mathrm{C}$ ) and then filtered through a $0.45-\mu \mathrm{m}$ bottle top vacuum filter (Corning, NY, USA). The filtered supernatant was concentrated using an Amicon Ultrafiltration system (Merck Millipore, Billerica, Massachusetts, USA) with a $100 \mathrm{kDa}$-exclusion filter, and subsequently subjected to ultracentrifugation $(2 \mathrm{~h}$, $150,000 g, 4^{\circ} \mathrm{C}$ ) in a Beckman type 70 Ti rotor (Beckman, CA, USA). The pellet containing OMVs was resuspended in sterile PBS ( $\mathrm{pH} 7.4)$ and further purified by OptiPrep density gradient centrifugation $\left(16 \mathrm{~h}, 180,000 g, 4{ }^{\circ} \mathrm{C}\right)$ with Optiprep (Sigma-Aldrich) concentrations ranging from $10 \%$ to $55 \%(\mathrm{w} / \mathrm{v})$ [26]. After centrifugation, each fraction from the top of the gradient to the bottom was collected to determine the particle number by nanoparticle tracking analysis (NTA). These fractions enriched with OMVs were pooled, diluted in sterile PBS and then centrifuged ( $2 \mathrm{~h}, 150,000 g, 4{ }^{\circ} \mathrm{C}$ ) to remove OptiPrep. Purified OMVs pellet was resuspended in sterile PBS, sterilized by filtration $(0.45 \mu \mathrm{m}$; Millipore, Bedford, MA), and finally stored at $-80{ }^{\circ} \mathrm{C}$ until future use.

The protein concentration of OMVs was measured by a bicinchoninic acid assay kit (Nanjing Jiancheng Bioengineering Institute, Jiangsu, China). The purified OMVs from these three APEC strains were uniformly mixed in equal proportions to formulate the final MOMVs. Outer membrane proteins (OMPs) were prepared from each APEC strain using the Sarkosyl method as described previously [53]. Multi-serogroup OMPs (MOMPs) were formulated in the same way as MOMVs and used to measure the anti-MOMPs IgG titer in sera. To remove vesicular lipopolysaccharide (LPS) and proteins, native
MOMVs were treated with an equal amount of polymyxin B (PMB_MOMVs) and $50 \mu \mathrm{g} / \mathrm{mL}(3 \mathrm{U} / \mathrm{mL})$ proteinase K (PK_MOMVs) according to previously reported methods, respectively $[54,55]$. Inactivation of proteinase $\mathrm{K}$ was performed by raising the temperature $\left(75^{\circ} \mathrm{C}\right.$ for $30 \mathrm{~min}$ ) and adding proteinase $\mathrm{K}$ inhibitor (Cocktail Set I, Sigma-Aldrich). Limulus Amebocyte Lysate (LAL) and SDS-PAGE electrophoresis assays were performed to confirm the effectiveness of the treatments. These MOMVs were used for subsequent vaccination of chickens.

\section{Characterization and proteomic analysis of MOMVs}

Purified MOMVs were visualized to detect their morphology and integrity by scanning electron microscopy and transmission electron microscopy using a Field Emission Scanning Electron Microscope (S-4800, Hitachi, Tokyo, Japan) and FEI Tecnai ${ }^{\mathrm{TM}}$ G2 Spirit BioTWIN (FEI Company, OR, USA), as described previously [56]. The diameter size distribution of MOMVs was assessed by NTA using a Nanoparticle Analyser (NanoSight, Malvern, Worchestershire, UK) with the operating parameters as follows: 15 for camera level, five 60 -s videos for each sample and 6 for detection threshold. To determine the proteome of MOMVs, proteins $(10 \mu \mathrm{g})$ of MOMVs were separated by $10 \%$ SDS-PAGE gel followed by staining with Coomassie Brilliant blue G250 (Sigma-Aldrich). Protein lanes were extracted from the gel, and then digested with trypsin. The obtained peptides were analyzed by the UPLC coupled to tandem mass spectrometry (MS/MS) (LC-MS/MS; Thermo Scientific) [57]. The resulting $\mathrm{MS} / \mathrm{MS}$ data from three independent experiments were processed separately using Maxquant search engine (v.1.5.2.8). For protein identification, mass spectra were matched with typical $E$. coli $\mathrm{K}-12$ strains in the UniProt database. All searches were filtered using the parameter settings described in a previous study [57]. The identified proteins were analyzed by subcellular localization as well as Gene Ontology (GO) biological processes and molecular functions using CELLO (http://cello.life. nctu.edu.tw/) and InterProScan (http://www.ebi.ac.uk/ interpro/), respectively.

\section{In vitro studies of chicken macrophage}

The HD11 cells, a transformed chicken macrophage cell line, were used to investigate whether MOMVs could induce innate immune responses in vitro. We first explored the uptake of MOMVs by HD11 macrophages using a co-culture experiment as described previously [17]. Briefly, dialkylcarbocyanine iodide (DiI, SigmaAldrich)-labeled MOMVs were co-cultured with HDl1 cells in complete PRMI-1640 medium (Gibco) containing $10 \%$ heat-inactivated FBS (HyClone) and antibiotics 
(100 U/mL penicillin and $100 \mu \mathrm{g} / \mathrm{mL}$ streptomycin, Sigma-Aldrich) at $37{ }^{\circ} \mathrm{C}$ in a $5 \% \mathrm{CO}_{2}$ atmosphere. After incubation, the cell nucleus was stained with 4, 6-diamidino-2-phenylindole (DAPI, Sigma-Aldrich) and then visualized with High-speed spinning-disk confocal microscope (Andor Revolution XD, Andor Technology, UK). The cells that were not treated with MOMVs were used as the control. We next performed a stimulation assay to evaluate the immune responses of chicken macrophage to MOMVs. HD11 monolayers $\left(1 \times 10^{6}\right.$ cells $/ \mathrm{mL}$ ) were cultured with various doses of MOMVs $(0-100 \mathrm{ng} / \mathrm{mL})$ in cell culture medium described above. After 16-h stimulation, the cell culture supernatants were collected for determining the production of cytokines.

\section{Determination of the lethal doses for APEC strains}

Three doses $\left(1 \times 10^{8}, 5 \times 10^{8}\right.$ and $\left.1 \times 10^{9} \mathrm{CFU}\right)$ of each APEC strain in $100 \mu \mathrm{L}$ PBS were administrated into chickens by the intratracheal route to determine the lethal dose (LD). The survival rate was recorded every day for 10 days.

\section{Immunization and challenge}

Prior to conducting animal experiments, specific PCR tests were used to ensure that the chickens were not infected with these three APEC strains [58]. To investigate the cross-protective efficacy of MOMVs immunization against APEC infections, 7-day-old chickens were vaccinated three times with 10,50 and $100 \mu \mathrm{g}$ of MOMVs in $100 \mu \mathrm{L}$ PBS at a 1-week interval via the intramuscular route, respectively (Fig. 6a, upper panel). Seven days after the third vaccination (day 28), the birds were infected with the LD of each APEC strain by the intratracheal route. The survival rate was monitored every day for 10 days. To examine the long-term protective effect of MOMVs immunization, chickens were immunized with an optimal dose of MOMVs, and then infected with $2 \times$ LD of each APEC strain 5 weeks after the last immunization (day 56). To evaluate the role of vesicular proteins and LPS in MOMVs-mediated protection, we used PMB_MOMVs and PK_MOMVs to immunize chickens, respectively, and observed the survival rate after infection with the LD of each APEC strain.

\section{Determination of specific antibody titer}

One week after each vaccination, sera from chickens were sampled for determining the levels of specific IgG against these three OMVs of the mixed MOMVs using an indirect ELISA method as described previously [22]. Briefly, the 96-well plates were coated with $200 \mathrm{ng}$ of each OMVs overnight at $4{ }^{\circ} \mathrm{C}$ and then blocked with $1 \%$ bull serum albumin. The sera were diluted by 200 -fold in PBS, and used as the primary antibody, which was then added in the blocked wells and incubated at $37{ }^{\circ} \mathrm{C}$ for $1 \mathrm{~h}$. The specific IgG was detected after the plates were incubated with secondary HRP-conjugated rabbit anti-chicken IgG (Sigma-Aldrich) followed by the addition of tetramethylbenzidine substrate. The absorbance at $450 \mathrm{~nm}$ was detected using a Microplate Reader (Epoch 2, Biotek, Winooski, USA). Each sample was detected in triplicate. The anti-LPS and anti-MOMPs IgG titer in sera were determined by the same method using purified LPS and MOMPs.

\section{Expression of immune genes}

Total RNA was extracted from spleen tissues of MOMVsand PBS-immunized birds at 1 week after the third immunization using a total RNA kit I (Omega BioTek, Norcross, GA, USA), and then reverse-transcribed into cDNA using the PrimeScript ${ }^{\mathrm{TM}}$ RT Reagent Kit with gDNA Eraser (TaKaRa Biotechnology, Dalian, China). Quantitative real-time PCR (qRT-PCR) for immunerelated genes (Table 1) was performed in a Real-Time PCR Detection System (CFX96 Touch, Bio-Rad, Hercules, CA, USA). The primers for the target genes and reference gene $(\beta$-actin) are listed in Additional file 4: Table S1. Each PCR reaction was conducted in triplicate, as follows: $95^{\circ} \mathrm{C}$ for $1 \mathrm{~min}, 40$ cycles of $95^{\circ} \mathrm{C}$ for $15 \mathrm{~s}$ and $60^{\circ} \mathrm{C}$ for $30 \mathrm{~s}$. Relative gene expression was presented as fold-change compared with the control using the $2^{-\Delta \Delta \mathrm{Ct}}$ method [59].

\section{Growth performance and blood parameters}

One week after the final immunization, daily feed intake (DFI), average daily weight gain (ADG), feed conversion ratio (FCR) and mortality for the entire period of immunization (days 7-28) were measured as described previously [60]. Blood samples were collected from MOMVs- and PBS-immunized chickens for determination of the number of white blood cells and platelets using an automatic blood cell analyzer (XFA6100; Perlong new technology Co., Ltd., Nanjing, China).

\section{Measurement of bacterial burden}

After APEC infection, bacterial burdens of liver and lung tissues were estimated at indicated times by qRT-PCR as described previously [61]. Briefly, DNA was isolated and purified from liver or lung tissues using a QIAamp DNA Kit (Qiagen, Shanghai, China), and bacterial burden was detected by using specific primers and a probe derived from $16 \mathrm{~S}$ rDNA sequences of $E$. coli, including the forward primer (5'-CATGCCGCGTGTATGAAGAA-3'), the reverse primer (5'CGGGTAACGTCAATGAG CAAA- $\left.3^{\prime}\right)$, and the detecting probe $\left(5^{\prime}\right.$-TATTAACTT TACTCCCTTCCTCCCCGCTGA A-3'). Bacterial burden was presented as the number of $16 \mathrm{~S}$ rDNA gene 
copies per unit of total DNA after normalization of total DNA content per unit of tissue for the same sample.

\section{Measurement of chicken cytokines}

The cytokine levels in serum and cell-culture supernatant were determined, including interleukin (IL)- 6 and tumor necrosis factor-alpha (TNF- $\alpha$ ) in serum collected at day 22 (24 $\mathrm{h}$ after the last immunization) and day 29 (24 $\mathrm{h}$ after challenge), IL-6, TNF- $\alpha$ and IL-12 in the supernatant of HD11 cells. Since chicken IL-12 has functional homologue and bioactive similarity with human IL-12, we used a human IL-12 ELISA kit (R\&D System) to determine chicken IL-12 levels [62]. The production of chicken IL- 6 and TNF- $\alpha$ were estimated using IL- 6 and TNF- $\alpha$ activity bioassays, respectively [63].

\section{Statistical analysis}

Graph Pad Prism software 5.0 was used for data analysis. Data are shown as the mean \pm standard error of the mean (SEM). Student's $t$-test was used for pairwise comparisons. Significant differences $(P<0.05)$ of means among three or more groups were analyzed using oneway ANOVA with the Newman-Keuls test as the post hoc test. The survival rates after bacteria challenge were compared by the log-rank test.

\section{Supplementary information}

Supplementary information accompanies this paper at https://doi. org/10.1186/s12934-020-01372-7.

Additional file 1: Fig. S1. Determination of the lethal dose of these three APEC serogroups (01, O2 and O78). Different doses $\left(1 \times 10^{8}, 5 \times 10^{8}\right.$ and $1 \times 10^{9} \mathrm{CFU}$ ) of APEC strains were injected by the intratracheal route into chickens $(n=10)$. Survival rates were recorded every day for 10 days.

Additional file 2: Fig. S2. Evaluation of the potential adverse effects from immunization with MOMVs. a Effect of immunization with MOMVs on growth performance of each group $(n=20)$ during the immunization period of 7-28 days, including daily feed intake, average daily weight gain and feed/gain ratio. $\mathbf{b}$ Effect of immunization with MOMVs on the number of white blood cells and platelets in blood from MOMVs- and PBS-immunized chickens at 7 days after the final immunization $(n=5) .{ }^{*} P<0.05$; ${ }^{*} P<0.01$; ${ }^{* *} P<0.001$; n.S., not significant; versus the control (PBS).

Additional file 3: Fig. S3. Bacterial CFU counting in liver tissue from MOMVs- and PBS immunized chickens. The liver samples were homogenized and then prepared with tenfold serial dilutions in sterile PBS and plated on LB agars in triplicate. The colonies were counted after overnight incubation at $37^{\circ} \mathrm{C}$.

Additional file 4: Table S1. Primers used for real-time PCR of immune genes in broiler chicken.

\section{Abbreviations}

APEC: Avian pathogenic Escherichia coli; E. col: Escherichia coli; OMVs: Outer

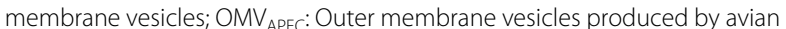
pathogenic Escherichia coli; $\mathrm{OMV}_{\mathrm{EC}}$ : Outer membrane vesicles produced by Escherichia coli; MOMVs: Multi-serogroup outer membrane vesicles; OMPs: Outer membrane proteins; MOMPs: Multi-serogroup outer membrane proteins; LPS: Lipopolysaccharide; PMB_MOMVs: Polymyxin B-treated MOMVs; PK_MOMVs: Proteinase K-treated MOMVs; NTA: Nanoparticle tracking analysis;
LAL: Limulus amebocyte lysate; LD: Lethal dose; DFI: Daily feed intake; ADG: Average daily weight gain; FCR: Feed conversion ratio.

\section{Acknowledgements}

We would like to thank State Key Laboratory of Crop Stress Biology for Arid Areas for providing the Optima L-100XP used in this study. We would like to thank China Veterinary Culture Collection Center for providing APEC strains used in this study. We would also like to thank Hangzhou PTM Biolabs for providing LC-MS/MS data analysis.

\section{Authors' contributions}

RJH, YPG and MMY designed the research; RJH and MMY mainly wrote the manuscript; $Y P G$ and $M M Y$ reviewed the manuscript; $R J H, J L, H L$ and $L L$ conducted the experiments; YZZ, MMW, HJL and YNM contributed to animal feeding and data analyses. All authors read and approved the final manuscript.

\section{Funding}

This study was supported by National Natural Science Foundation of China (No. 31672437).

\section{Availability of data and materials}

All data generated or analyzed during this study are included in this published article and its additional file.

\section{Ethics approval and consent to participate}

Experimental procedures and animal use were approved by the Northwest A\&F University Animal Care and Use Committee.

\section{Consent for publication}

Not applicable.

\section{Competing interests}

We declare that we have no competing interests.

\section{Author details}

${ }^{1}$ College of Animal Science and Technology, Northwest A\&F University, Yangling 712100, Shaanxi, China. ${ }^{2}$ Department of Animal Engineering, Yangling Vocation and Technical College, Yangling 712100, Shaanxi, China.

Received: 21 February 2020 Accepted: 16 May 2020

Published online: 03 June 2020

References

1. Dho-Moulin M, Fairbrother JM. Avian pathogenic Escherichia coli (APEC). Vet Res. 1999;30:299-316.

2. Collingwood C, Kemmett K, Williams N, Wigley P. Is the concept of avian pathogenic Escherichia coli as a single pathotype fundamentally flawed? Front Vet Sci. 2014;1:5-5.

3. Wang S, Peng Q, Jia HM, Zeng XF, Zhu JL, Hou CL, Liu XT, Yang FJ, Qiao SY. Prevention of Escherichia coli infection in broiler chickens with Lactobacillus plantarum B1. Poult Sci. 2017:96:2576-86.

4. Johnson TJ, Wannemuehler Y, Johnson SJ, Stell AL, Doetkott C, Johnson JR, Kim KS, Spanjaard L, Nolan LK. Comparison of extraintestinal pathogenic Escherichia coli strains from human and avian sources reveals a mixed subset representing potential zoonotic pathogens. Appl Environ Microb. 2008;74:7043-50.

5. Tivendale KA, Logue CM, Kariyawasam S, Jordan D, Hussein A, Li GW, Wannemuehler Y, Nolan LK. Avian-pathogenic Escherichia coli strains are similar to neonatal meningitis E coli strains and are able to cause meningitis in the rat model of human disease. Infect Immun. 2010;78:3412-9.

6. Bélanger L, Garenaux A, Harel J, Boulianne M, Nadeau E, Dozois CM. Escherichia coli from animal reservoirs as a potential source of human extraintestinal pathogenic E. coli. FEMS Immunol Med Mic. 2011;62:1-10.

7. Wang XM, Liao XP, Zhang WJ, Jiang HX, Sun JA, Zhang MJ, He XF, Lao DX, Liu YH. Prevalence of serogroups, virulence genotypes, antimicrobial resistance, and phylogenetic background of avian pathogenic Escherichia coli in south of China. Foodborne Pathog Dis. 2010;7:1099-106.

8. Johnson JR, Sannes MR, Croy C, Johnston B, Clabots C, Kuskowski MA, Bender J, Smith KE, Winokur PL, Belongia EA. Antimicrobial drug-resistant 
Escherichia coli from humans and poultry products, Minnesota and Wisconsin, 2002-2004. Emerg Infect Dis. 2007;13:838-46.

9. Ghunaim H, Abdelhamid MA, Kariyawasam S. Advances in vaccination against avian pathogenic Escherichia coli respiratory disease: potentials and limitations. Vet Microbiol. 2014;172:13-22.

10. Chaudhari AA, Lee JH. Evaluation of the adjuvant effect of Salmonellabased Escherichia coli heat-labile toxin B subunits on the efficacy of a live Salmonella-delivered avian pathogenic Escherichia coli vaccine. Avian Pathol. 2013:42:365-72.

11. Schwechheimer C, Kuehn MJ. Outer-membrane vesicles from Gram-negative bacteria: biogenesis and functions. Nat Rev Micro. 2015;13:605-19.

12. Kim JH, Lee J, Park J, Gho YS. Gram-negative and Gram-positive bacterial extracellular vesicles. Semin Cell Dev Biol. 2015;40:97-104.

13. Unal CM, Schaar V, Riesbeck K. Bacterial outer membrane vesicles in disease and preventive medicine. Semin Immunopathol. 2011;33:395-408.

14. Chen DJ, Osterrieder N, Metzger SM, Buckles E, Doody AM, DeLisa MP, Putnam D. Delivery of foreign antigens by engineered outer membrane vesicle vaccines. P Natl Acad Sci. 2010;107:3099-104.

15. Zhang XL, Yang F, Zou JT, Wu WR, Jing HM, Gou Q, Li HB, Gu J, Zou $\mathrm{QM}$, Zhang JY. Immunization with Pseudomonas aeruginosa outer membrane vesicles stimulates protective immunity in mice. Vaccine. 2018;36:1047-54.

16. Liu Q, Liu Q, Yi J, Liang K, Liu T, Roland KL, Jiang YL, Kong QK. Outer membrane vesicles derived from Salmonella Typhimurium mutants with truncated LPS induce cross-protective immune responses against infection of Salmonella enterica serovars in the mouse model. Int J Med Microbiol. 2016;306:697-706.

17. Lee WH, Choi HI, Hong SW, Kim KS, Gho YS, Jeon SG. Vaccination with Klebsiella pneumoniae-derived extracellular vesicles protects against bacteria-induced lethality via both humoral and cellular immunity. Exp Mol Med. 2015:47:e183.

18. Mitra S, Chakrabarti MK, Koley H. Multi-serotype outer membrane vesicles of Shigellae confer passive protection to the neonatal mice against shigellosis. Vaccine. 2013;31:3163-73.

19. Roier S, Leitner DR, Iwashkiw J, Schild-Prufert K, Feldman MF, Krohne G, Reidl J, Schild S. Intranasal immunization with nontypeable Haemophilus influenzae outer membrane vesicles induces cross-protective immunity in mice. PLOS ONE. 2012;7:e42664.

20. Holst J, Martin D, Arnold R, Huergo CC, Oster P, O'Hallahan J, Rosenqvist E. Properties and clinical performance of vaccines containing outer membrane vesicles from Neisseria meningitidis. Vaccine. 2009;27:B3-12.

21. Vanaja Sivapriya K, Russo Ashley J, Behl B, Banerjee I, Yankova M, Deshmukh Sachin D, Rathinam Vijay AK. Bacterial outer membrane vesicles mediate cytosolic localization of LPS and caspase-11 activation. Cell. 2016;165:1106-19.

22. Kim OY, Hong BS, Park K-S, Yoon YJ, Choi SJ, Lee WH, Roh T-Y, Lotvall J, Kim Y-K, Gho YS. Immunization with Escherichia coli outer membrane vesicles protects bacteria-induced lethality via Th1 and Th17 cell responses. J Immunol. 2013;190:4092-102.

23. Park K-S, Choi K-H, Kim Y-S, Hong BS, Kim OY, Kim JH, Yoon CM, Koh G-Y, Kim Y-K, Gho YS. Outer membrane vesicles derived from Escherichia coli induce systemic inflammatory response syndrome. PLOS ONE. 2010:5:e11334

24. Jain S, Pillai J. Bacterial membrane vesicles as novel nanosystems for drug delivery. Int J Nanomed. 2017:12:6329-41.

25. Molloy MP, Herbert BR, Slade MB, Rabilloud T, Nouwens AS, Williams KL, Gooley AA. Proteomic analysis of the Escherichia coli outer membrane. Eur J Biochem. 2000;267:2871-81.

26. Prados-Rosales R, Brown L, Casadevall A, Montalvo-Quirós S, Luque-Garcia $\mathrm{JL}$. Isolation and identification of membrane vesicle-associated proteins in Gram-positive bacteria and mycobacteria. MethodsX. 2014;1:124-9.

27. Wang H, Liang K, Kong Q, Liu Q. Immunization with outer membrane vesicles of avian pathogenic Escherichia coli $\mathrm{O} 78$ induces protective immunity in chickens. Vet Microbiol. 2019;236:108367.

28. Pillai S, Howell A, Alexander K, Bentley BE, Jiang HQ, Ambrose K, Zhu DZ, Zlotnick G. Outer membrane protein (OMP) based vaccine for Neisseria meningitidis serogroup B. Vaccine. 2005;23:2206-9.

29. Lee E-Y, Bang JY, Park GW, Choi D-S, Kang JS, Kim H-J, Park K-S, Lee J-O, Kim Y-K, Kwon K-H, et al. Global proteomic profiling of native outer membrane vesicles derived from Escherichia coli. Proteomics. 2007;7:3143-53.
30. Kuehn MJ, Kesty NC. Bacterial outer membrane vesicles and the hostpathogen interaction. Gene Dev. 2005;19:2645-55.

31. Bishop D, Work E. An extracellular glycolipid produced by Escherichia coli grown under lysine-limiting conditions. Biochem J. 1965;96:567.

32. Work E, Knox K, Vesk M. The chemistry and electron microscopy of an extracellular lipopolysaccharide from Escherichia coli. Ann Ny Acad of Sci. 1966;133:438-49.

33. Levine MM, Sztein MB. Vaccine development strategies for improving immunization: the role of modern immunology. Nat Immunol. 2004;5:460-4.

34. Fransen F, Boog CJ, van Putten JP, van der Ley P. Agonists of toll-like receptors $3,4,7$, and 9 are candidates for use as adjuvants in an outer membrane vaccine against Neisseria meningitidis serogroup B. Infect Immun. 2007;75:5939-46.

35. Lee E-Y, Choi D-S, Kim K-P, Gho YS. Proteomics in gram-negative bacterial outer membrane vesicles. Mass Spectrom Rev. 2008;27:535-55.

36. Collins BS. Gram-negative outer membrane vesicles in vaccine development. Discov Med. 2011;12:7-15.

37. Brown L, Wolf JM, Prados-Rosales R, Casadevall A. Through the wall: extracellular vesicles in Gram-positive bacteria, mycobacteria and fungi. Nat Rev Micro. 2015;13:620-30.

38. Kaparakis-Liaskos M, Ferrero RL. Immune modulation by bacterial outer membrane vesicles. Nat Rev Immunol. 2015;15:375-87.

39. Greatorex JS, Thorne GM. Humoral immune responses to Shiga-like toxins and Escherichia coli 0157 lipopolysaccharide in hemolytic-uremic syndrome patients and healthy subjects. J Clin Microbiol. 1994;32:1172-8.

40. LeBlanc J, Fliss I, Matar C. Induction of a humoral immune response following an Escherichia coli O157: h7 infection with an immunomodulatory peptidic fraction derived from Lactobacillus helveticus-fermented milk. Clin Diagn Lab Immunol. 2004;11:1171-81.

41. Varin A, Gordon S. Alternative activation of macrophages: immune function and cellular biology. Immunobiology. 2009;214:630-41.

42. Zhou HJ, Lamont SJ. Chicken MHC class I and II gene effects on antibody response kinetics in adult chickens. Immunogenetics. 2003;55:133-40.

43. Stromberg ZR, Van Goor A, Redweik GAJ, Mellata M. Characterization of spleen transcriptome and immunity against avian colibacillosis after immunization with recombinant attenuated Salmonella vaccine strains. Front Vet Sci. 2018:5:198.

44. Shahin R, Brennan M, Li Z, Meade B, Manclark C. Characterization of the protective capacity and immunogenicity of the $69-k D$ outer membrane protein of Bordetella pertussis. J Exp Med. 1990;171:63-73.

45. Korn A, Rajabi Z, Wassum B, Ruiner W, Nixdorff K. Enhancement of uptake of lipopolysaccharide in macrophages by the major outermembrane protein OmpA of Gram-negative bacteria. Infect Immun. 1995;63:2697-705.

46. Liu CY, Chen ZH, Tan C, Liu WG, Xu ZF, Zhou R, Chen HC. Immunogenic characterization of outer membrane porins $\mathrm{OmpC}$ and $\mathrm{OmpF}$ of porcine extraintestinal pathogenic Escherichia coli. FEMS Microbiol Lett. 2012:337:104-11

47. Kapur V, White DG, Wilson RA, Whittam TS. Outer-membrane proteinpatterns mark clones of Escherichia coli $\mathrm{O} 2$ and $\mathrm{O} 78$ strains that cause avian septicemia. Infect Immun. 1992;60:1687-91.

48. Scorza FB, Doro F, Rodriguez-Ortega MJ, Stella M, Liberatori S, Taddei AR, Serino L, Moriel DG, Nesta B, Fontana MR, et al. Proteomics characterization of outer membrane vesicles from the extraintestinal pathogenic Escherichia coli $\Delta$ tolR IHE3034 mutant. Mol Cell Proteomics. 2008;7:473-85.

49. Jan AT. Outer membrane vesicles (OMVs) of Gram-negative bacteria: a perspective update. Front Microbiol. 2017;8:1053.

50. Kim OY, Choi SJ, Jang SC, Park KS, Kim SR, Choi JP, Lim JH, Lee SW, Park J, Di Vizio D, et al. Bacterial pprotoplast-derived nanovesicles as vaccine delivery system against bacterial infection. Nano Lett. 2015;15:266-74.

51. Chutkan H, MacDonald I, Manning A, Kuehn MJ. Quantitative and qualitative preparations of bacterial outer membrane vesicles. In: Delcour HA, Totowa NJ, editors. Bacterial cell surfaces: methods and protocols. New York: Humana Press; 2013. p. 259-72.

52. Klimentová J, Stulík J. Methods of isolation and purification of outer membrane vesicles from Gram-negative bacteria. Microbiol Res. 2015;170:1-9. 
53. Kesty NC, Kuehn MJ. Incorporation of heterologous outer membrane and periplasmic proteins into Escherichia coli outer membrane vesicles. J Biol Chem. 2004;279:2069-76.

54. Morrison DC, Jacobs DM. Binding of polymyxin B to the lipid A portion of bacterial lipopolysaccharides. Immunochemistry. 1976;13:813-8.

55. Kaparakis M, Turnbull L, Carneiro L, Firth S, Coleman HA, Parkington HC, Le Bourhis L, Karrar A, Viala J, Mak J, et al. Bacterial membrane vesicles deliver peptidoglycan to NOD1 in epithelial cells. Cell Microbiol. 2010;12:372-85.

56. Brown L, Kessler A, Cabezas-Sanchez P, Luque-Garcia JL, Casadevall A. Extracellular vesicles produced by the Gram-positive bacterium Bacillus subtilis are disrupted by the lipopeptide surfactin. Mol Microbiol. 2014:93:183-98.

57. Niemann M, Wiese S, Mani J, Chanfon A, Jackson C, Meisinger C, Warscheid B, Schneider A. Mitochondrial outer membrane proteome of Trypanosoma brucei reveals novel factors required to maintain mitochondrial morphology. Mol Cell Proteomics. 2013;12:515-28.

58. Wang S, Meng Q, Dai J, Han X, Han Y, Ding C, Liu H, Yu S. Development of an allele-specific PCR assay for simultaneous sero-typing of avian pathogenic Escherichia coli predominant 01, 02, 018 and 078 strains. PLOS ONE. 2014;9:e96904.
59. Livak KJ, Schmittgen TD. Analysis of relative gene expression data using real-time quantitative PCR and the $2^{-\Delta \Delta \mathrm{Ct}}$ method. Methods. 2001;25:402-8

60. Massuquetto A, Panisson JC, Marx FO, Surek D, Krabbe EL, Maiorka A. Effect of pelleting and different feeding programs on growth performance, carcass yield, and nutrient digestibility in broiler chickens. Poult Sci. 2019;98:5497-503.

61. Huijsdens XW, Linskens RK, Mak MT, Meuwissen SGM, VandenbrouckeGrauls CMJE, Savelkoul PHM. Quantification of bacteria adherent to gastrointestinal mucosa by real-time PCR. J Clin Microbiol. 2002;40:4423-7.

62. Degen WGJ, van Daal N, van Zuilekom HI, Burnside J, Schijns VEJC. Identification and molecular cloning of functional chicken IL-12. J Immunol. 2004;172:4371-80.

63. Rath NC, Huff WE, Bayyari GR, Balog JM. Identification of transforming growth factor- $\beta$ and interleukin- 6 in chicken ascites fluid. Avian Dis. 1995:39:382-9.

\section{Publisher's Note}

Springer Nature remains neutral with regard to jurisdictional claims in published maps and institutional affiliations.
Ready to submit your research? Choose BMC and benefit from:

- fast, convenient online submission

- thorough peer review by experienced researchers in your field

- rapid publication on acceptance

- support for research data, including large and complex data types

- gold Open Access which fosters wider collaboration and increased citations

- maximum visibility for your research: over $100 \mathrm{M}$ website views per year

At BMC, research is always in progress.

Learn more biomedcentral.com/submissions 